archives

of thermodynamics

Vol. 36(2015), No. 1, 157-170

DOI: $10.1515 /$ aoter-2015-0011

\title{
Technical and economic aspects of oxygen separation for oxy-fuel purposes
}

\author{
MACIEJ CHOROWSKI \\ WOJCIECH GIZICKI ${ }^{1}$
}

Wroclaw University of Technology, Department of Cryogenic, Aeronautical and Process Engineering, Wybrzeze Wyspianskiego 27, 50-370 Wroclaw

\begin{abstract}
Oxy combustion is the most promising technology for carbon dioxide, originated from thermal power plants, capture and storage. The oxygen in sufficient quantities can be separated from air in cryogenic installations. Even the state-of-art air separation units are characterized by high energy demands decreasing net efficiency of thermal power plant by at least $7 \%$. This efficiency decrease can be mitigated by the use of waste nitrogen, e.g., as the medium for lignite drying. It is also possible to store energy in liquefied gases and recover it by liquid pressurization, warm-up to ambient temperature and expansion. Exergetic efficiency of the proposed energy accumulator may reach $85 \%$.
\end{abstract}

Keywords: Air separation; Oxy-combustion; Energy storage

\section{Introduction}

Black coal and lignite is a predominant type of fuel used for industrial power generation in Poland. It will stay unchanged in the near foreseeable future. Coal combusted at power plants and combined heat and power plants is a major source of emissions of carbon dioxide to the atmosphere. Oxy-combustion is one of the most promising, currently under consideration, technologies aimed to reduce emissions of carbon dioxide $\left(\mathrm{CO}_{2}\right)$. In this technology pure oxygen $\left(\mathrm{O}_{2}\right)$ (instead of air) is provided to boilers. Together with exhaust fumes being recirculated it leads to such a level of

\footnotetext{
${ }^{1}$ Corresponding Autor: E-mail: wojciech.gizicki@pwr.edu.pl
} 
concentration of carbon dioxide in exhaust fumes that its direct sequestration can be performed omitting the process of separation. The main cost in the process of oxy-combustion refers to energy consumed to separate oxygen from the air. This energy is substantial and at modern cryogenic installations it amounts to about $200 \mathrm{kWh} / \mathrm{t}$ of oxygen, still exceeding thermodynamic minimum by about four times. Assuming that an exemplary power block with its power of $500 \mathrm{MW}$ requires to provide about $9000 \mathrm{t}$ of oxygen per day, necessary electrical power to separate oxygen will be of about $75 \mathrm{MW}$ and will cause a significant drop (of about 7\%) in the efficiency of net electricity generation.

The paper outlines the current state of development and prospects of various technologies of oxygen separation from the air. It presents the specificity of quality requirements for oxygen to be used for industrial power generation (in particular capabilities to reduce its purity). This specificity allows certain modifications in reference to typical installations, which allow reducing the energy-consumption of oxygen separation. The paper also presents capabilities for integration of air separation units with installations of power generation, which allow making use of waste energy fluxes. Moreover, its demonstrates capabilities for utilisation of by-products derived from the process of oxygen separation such as nitrogen to increase the efficiency of energy generation, for example, through drying of coal provided to boilers or accumulation of exergy in liquefied nitrogen. The appropriate utilisation of these capabilities will allow to reduce energy consumed as required by oxygen separation and lower an adverse decline of the efficiency of energy generation in the oxy-combustion technology.

\section{Technologies of oxygen separation from the air}

Oxygen began to be used at an industrial scale - mainly in metallurgy from the early 20th century. At present, the application of this gas in thermal power generation has become more and more important. It is used in the processes of gasification and combustion of fuels in the oxygenic atmosphere. The air, which surrounds us is the main source of oxygen (at about $20.9 \%$ ). The rest is made of nitrogen, argon and traces of other components. All these three components are applied in modern technologies. To separate oxygen from the air (or possibly nitrogen and argon) it is required to apply one of the methods of air separation being available. These methods can be generally divided into two categories: cryogenic and noncryogenic ones. 
The cryogenic methods make use of differences in condensation temperatures of particular gases. The process of separation takes place in rectifying columns after prior cooling of air down to its condensation temperature. The main energy cost refers to the operation of air compressors. Air compression is required to obtain an appropriate level of cooling power and to overcome pressure drops during gas flows. Linde double columns, optionally with argon column are used at present installations. Such solutions allow achieving a very high state of purity of separation products (oxygen, nitrogen, argon). Cryogenic installations also allow to get the highest possible efficiencies of gas separation.

The noncryogenic methods mainly include adsorption and membranebased methods. And the adsorption methods are of the greatest importance. They are based on adsorption capabilities of nitrogen at the surface of beds (for example zeolite). Oxygen and argon flows further to the tank. Nitrogen from beds is removed by lowering the pressure (PSA - pressure swing adsorption). The process runs cyclically and requires appropriately compressed air to be supplied. Oxygen obtained in this method has a purity at about $95 \%$. It is not possible to obtain other separation products (nitrogen, argon) - there is about $11 \%$ of oxygen in waste fluxes. There are two membrane-based methods. The first one makes use of polymer membranes and allow to obtain only slight oxygen compaction up to about $40 \%$. The second one makes use of membranes with a transport of ions (ITM). In this case it is possible to get practically $100 \%$ of oxygen purity but this method has currently been under research and its efficiencies obtained are low. The summary of the above-specified methods of oxygen separation together with their most important features is shown in Tab. 1.

In case of oxygen separation for energy purposes, in quantities closely correlated to requirements of thermal power plants, a level of energy consumption of the process of oxygen separation is a very relevant factor. Furthermore, it is important whether energy supplied to air separation units may take other forms (for example thermal energy). The usability of thermal energy allows the potential coupling of air separation installations with systems used to generate electricity in cogeneration, solar collectors and waste energy sources. When a power plant is required to work at varied loads (which can be caused by increase shares of energy from renewable sources in the energy mix), it is also justified to analyse the possibilities of energy accumulation in air separation products, in particular in liquefied oxygen, nitrogen, argon and compressed gases. The dynamic properties of 
installations of air separation are relevant in case of varied loads at the power plant, which can also be caused by a high share of energies derived from renewable sources in the energy mix.

Table 1: Comparison of air separation technologies.

\begin{tabular}{|c|c|c|c|c|c|}
\hline $\begin{array}{c}\text { Technology } \\
\text { Development } \\
\text { stage }\end{array}$ & $\begin{array}{c}\mathrm{O}_{2} \\
\text { purity } \\
{[\%]}\end{array}$ & $\begin{array}{c}\text { Capacity } \\
\text { (single train) } \\
\text { [tonne/day] }\end{array}$ & $\begin{array}{c}\text { Possible } \\
\text { by-products } \\
\text { Their quality }\end{array}$ & $\begin{array}{l}\text { Driving } \\
\text { force }\end{array}$ & $\begin{array}{l}\text { Start-up } \\
\text { time }\end{array}$ \\
\hline $\begin{array}{c}\text { Cryogenic } \\
\text { Matured }\end{array}$ & $>99$ & $\begin{array}{l}\text { up to } \\
4000\end{array}$ & $\begin{array}{l}\text { Nitrogen, Argon, } \\
\text { Krypton, Xenon } \\
\text { Very good }\end{array}$ & Electricity & $\begin{array}{c}\text { Hours / } \\
\text { days }\end{array}$ \\
\hline $\begin{array}{l}\text { Adsorption } \\
\text { Matured }\end{array}$ & $\sim 95$ & up to 300 & $\begin{array}{c}\text { Nitrogen } \\
\text { Bad, ca. } 11 \% \\
\mathrm{O}_{2}\end{array}$ & $\begin{array}{l}\text { Electricity } \\
\text { Heat } \\
\left(70-90{ }^{\circ} \mathrm{C}\right)\end{array}$ & $\begin{array}{l}\text { Minutes/ } \\
\text { hours }\end{array}$ \\
\hline $\begin{array}{l}\text { Membrane } \\
\text { (polymer) } \\
\text { Matured }\end{array}$ & $\sim 40$ & up to 20 & $\begin{array}{l}\text { Nitrogen } \\
\text { Bad }\end{array}$ & Electricity & Minutes \\
\hline $\begin{array}{c}\text { Membrane } \\
\text { (ITM) } \\
\text { R\&D* phase }\end{array}$ & $>99$ & $\begin{array}{c}\text { laboratory } \\
\text { scale }\end{array}$ & $\begin{array}{l}\text { Nitrogen } \\
\text { Bad }\end{array}$ & $\begin{array}{c}\text { Electricity } \\
\text { Heat } \\
\left(800^{\circ} \mathrm{C}\right)\end{array}$ & Hours \\
\hline
\end{tabular}

* Research and development

The selection of an appropriate method of oxygen separation from the atmospheric air depends on a required scale of production of this gas, its purity and needed purity of gas waste fluxes, which can be valuable by-products such as for example nitrogen, argon or noble gases, krypton and xenon.

In case of oxygenic combustion, a level of performance of installations and energy-consumption of the process is the key criterion while selecting a method of air separation. As shown in Tab. 1, the cryogenic and adsorption methods only are characterised by their capacities, which meet the needs of thermal energy installations. Assuming 500 tons of oxygen per day to be an economically reasonable threshold of the efficiency of adsorption installations, installations of these types can cooperate with power blocks with their powers not exceeding $25 \mathrm{MW}_{e}$. Thermal power stations with their powers exceeding $25 \mathrm{MW}_{e}$ should be linked with cryogenic installations of air separation. Pilot installations, laboratory installations and oxygen combustion installations at units with minor capacities (distributed cogeneration, waste incineration plants, steelworks and other) can be supplied with oxygen from adsorption and membrane-based installations. It 
is also possible to cyclically supply these minor installations with liquefied oxygen supplied in mobile tanks.

\section{Oxygen availibility in Poland}

Metallurgy is a branch of industry, which generates a high demand for oxygen. Historically, it was a driving force of the development of industrial production of oxygen and afterwards other technical gases. Mining industry is closely linked with metallurgy. Within the area of location of mines and metallurgic plants, in most cases there are also installations of air separation situated. In Poland the largest number of such installations is to be found within the areas of coal and copper mines. Figure 1 shows places of air separation installations of the main companies together with their efficiencies of oxygen separation.

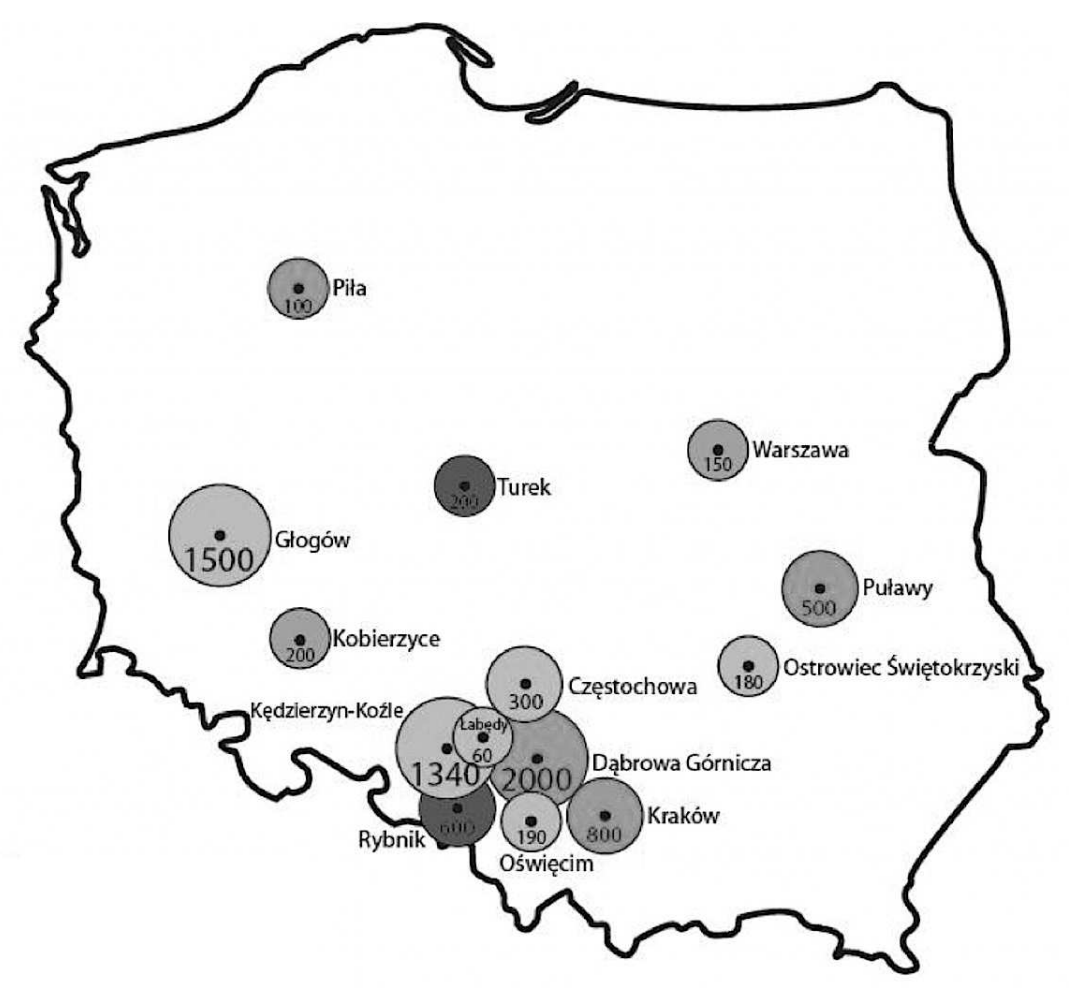

Figure 1: Production of oxygen in Poland (capacity in tonne/day). 
At present, about $9000 \mathrm{t}$ of oxygen per day is produced in Poland. A share of cryogenic installations in this number amounts to over $95 \%$. The rest is generated in minor adsorption installations. Without the extension of the existing infrastructure, Polish installations are in a position to provide about $1700 \mathrm{t}$ of oxygen per day for the needs of oxy-combustion. This amount meets the needs of a thermal block with its electrical power at about $100 \mathrm{MW}$. Collection and transportation of oxygen even to such a small power block causes huge logistical difficulties. Currently used mobile tanks have their capacity of about $20 \mathrm{t}( \pm 2 \mathrm{t})$. It generates a demand for about 85 mobile tanks daily. Unloading of an individual mobile tank takes about 30 to $50 \mathrm{~min}$, which - when in perfect synchronisation of supplies - would allow unloading 85 mobile tanks at two posts daily. Under worse conditions, to ensure the supply of oxygen, it would be necessary to concurrently operate four posts. On the other hand, it would make mobile tanks come to the plant every $17 \mathrm{~min}$ throughout the day. In view of these facts, the only possibility to ensure the supply of oxygen for industrial power generation purposes is to build a dedicated cryogenic installation of oxygen separation located at the thermal power plant site.

\section{Energy costs of oxygen separation}

The thermodynamically specified minimal energy demand of oxygen separation from the air is equal at $53.1 \mathrm{kWh} / \mathrm{t}$ of oxygen. Currently built installations of air separation are characterised by increasingly higher thermodynamic capabilities (still the best of them are characterised by their demand for energy exceeding the minimal requirements more than three times). Figure 2 shows the dynamics of improved thermodynamic efficiency of installations of air separation within 50 years. The data concern cryogenic installations and a reduced demand for operation is primarily the result of their economies of scale (which stands for improved efficiency of installations along with its increased efficiency). In cryogenic installations, their economies of scale are due to that the efficiency of an individual installation is proportional to its capacity, whereas the losses resulted from heat flows through insulation are proportional to external surfaces of lowtemperature equipment. Thus, as the efficiency of cryogenic installations increases, a ratio of losses to product fluxes decreases [1].

Taking into consideration the expected (in the future) increased efficiency of air separation installations, their resulted economies of scale and 


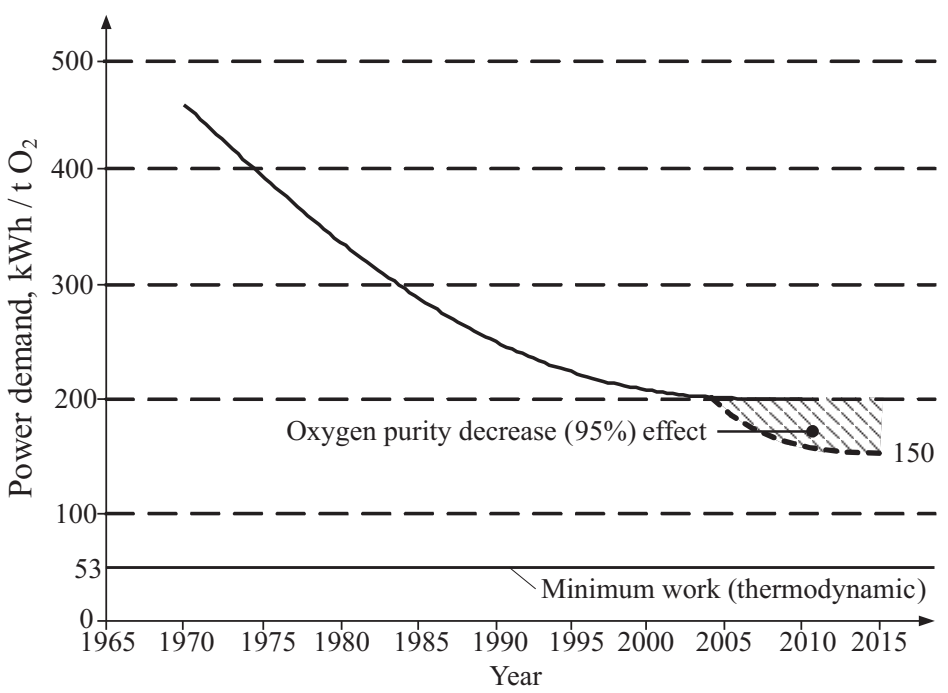

Figure 2: Development over time of energy demand for oxygen separation [2].

decreased energy-consumption caused by a reduction of requirements on oxygen purity, it can be forecasted that forthcoming installations will be characterised by their energy-consumption equal to about $150 \mathrm{kWh} / \mathrm{t}$ of oxygen $(540 \mathrm{~kJ} / \mathrm{kg} \mathrm{O}$ ). A further significant decrease of this ratio seems unlikely due to that there is no technical capability to increase the efficiency of individual technological lines and, thus, there are no effects of scale in future installations with numerous parallel operating technological lines.

Energy consumption of oxygen separation increases as a function of its purity. In spite of fact that cryogenic rectification provides oxygen with its very high purity (compare Tab. 1), this feature is not crucial in the process of oxy-combustion. Taking into account the energy consumption for air separation and further compression of the flue gases containing up to $90 \%$ of $\mathrm{CO}_{2}$, an optimal level of oxygen purity leaving the air separation unit (ASU) is about 95\% [2,3]. Cryogenic installations used as ASU integrated with thermal power plants should be adapted by decreasing the oxygen quality in comparison with standard state-of-art processes. Such adaptation should lead to a significant drop of energy consumption. There are a number of research and development $(\mathrm{R} \& \mathrm{D})$ projects aimed at both oxygen purity and elementary energy consumption decrease. A decrease of oxygen purity to $95 \%$ can be accompanied by a reduction of energy consumption by at least $10 \%[4-7]$. 


\section{Integration of air separation units with power generation installations}

Energy required to separate oxygen must be obtained at the cost of some energy produced in a power block implementing the technology of oxygenic combustion. Exhaust fumes (with a high level of concentration of carbon dioxide) generated as a result of combustion in pure oxygen in order to be subjected to sequestration should be previously compressed resulting in the consumption of energy connected with the operation of compression. Energy consumed for these two processes causes a significant drop in the efficiency of the power block. In view of the apparent saturation of the curve illustrating a decline of the energy consumption of cryogenic installations of oxygen separation from the air (Fig. 2) there are increasingly lower capabilities to improve the efficiency of the process itself. In order to improve the economics, the focus should be made at the utilisation of specific conditions related to the application of oxygenic combustion of coal in power generation. One of the possibilities of improvement is to make use of nitrogen as a by-product from the installation of air separation.

\subsection{Use of waste nitrogen to dry coal}

Lignite is a type of energy fuel widely used in Poland. It results from its abundant deposits and low prices. It is now, in terms of its calorific value, the cheapest source of electrical energy in Poland. Lignite is characterised by a very high level of moisture (about $50 \%$ ). It is possible to significantly increase its net calorific value through predrying. This process leads to a significant increase in the efficiency of electricity generation at plant powered with lignite.

As a standard, the process of drying is run by blowing it with hot air. In our conditions ambient air is characterised by a high level of relative humidity and the possibility of its collection from coal is significantly reduced. In order to intensify the process of drying and make is possible to absorb more water vapour from dry coal, air is required to be heated. Its raised temperature leads to increased saturation pressure of water vapour and decreased relative humidity of air itself.

Oxygen separation from the air requires large amounts of energy and causes a drop in the total efficiency of electricity generation at power plants. In the cryogenic process of oxygen separation, a substantial (about 4 times larger) flux of nitrogen is a waste product. This nitrogen occurs at ambi- 
ent temperatures but - due to the specificity of the cryogenic process - its relative humidity is practically zero percent. Therefore, it is highly capable to collect moisture at the drying of coal. Even without additional heating. The efficiency of electricity generation, which lost in relation to energy consumed for oxygen separation, can be - to some extent - recovered through the drying of lignite by means of a flux of waste nitrogen. In addition, if heat generated by compressors in the cryogenic installation was used and a temperature of dry nitrogen was increased, its capability to absorb moisture would increase even more.

A simulation analysis was conducted on the impact of drying of lignite with a flux of dry nitrogen onto the increase in the efficiency of electricity generation. The following assumptions were adopted for the analysis:

- electric power of the unit, $100 \mathrm{MW}$

- electric efficiency of the unit, $35 \%$

- composition of lignite corresponding to one of the domestic coals, including its content of moisture, $42.1 \%$

- relative humidity of nitrogen upon departing an ASU, 0\%

- relative humidity of nitrogen upon departing a drying unit, $100 \%$

The calorific value of coal was calculated on the basis of the Mendeleyev formula. For such selected coal and power of the block, a flux of fuel and oxygen was specified as required in the technology of oxy-combustion. A flux of nitrogen is determined by a flux of oxygen and composition of air. The process of drying had an impact onto the reduction of content of moisture in coal and - indirectly - onto the share of other components. It led to its increased calorific value and decreased required flow of fuel. Therefore, it also changed a flux of oxygen and amount of nitrogen projected for drying. Having regard to all these dependencies, a simulation was performed on the impact of a temperature of waste nitrogen flux used to dry coal onto the content of moisture in coal, increased calorific values and, finally, onto decreased consumption of coal in the power block. The results are presented in Tab. 2.

On the grounds of the stimulation it was shown that - making use of a full flux of waste nitrogen which is generated in an air separation unit (ASU) adjusted to a specified power of the block - it is possible to achieve increased calorific values of lignite by $6 \%$ and decreased consumption of fuel by about $5.6 \%$. It takes place when nitrogen is at ambient temperature. 
Table 2: The impact of a temperature of waste dry nitrogen onto the improvement of parameters of the thermal block as a result of drying of lignite (the original content of moisture in coal was equal to $42.1 \%$ )

\begin{tabular}{|c|c|c|c|c|}
\hline $\begin{array}{c}\text { Temperature } \\
\text { of nitrogen } \\
{\left[{ }^{\circ} \mathrm{C}\right]}\end{array}$ & $\begin{array}{c}\text { Content of } \\
\text { lignite moisture } \\
\text { after drying } \\
{[\%]}\end{array}$ & $\begin{array}{c}\text { Increase } \\
\text { in calorific } \\
\text { value } \\
{[\%]}\end{array}$ & $\begin{array}{c}\text { Reduction in } \\
\text { coal } \\
\text { consumption } \\
{[\mathrm{t} / \text { day }]}\end{array}$ & $\begin{array}{c}\text { Reduction in } \\
\text { coal } \\
\text { consumption } \\
{[\%]}\end{array}$ \\
\hline \hline 10 & 40.7 & 3.0 & 74 & 2.9 \\
\hline 20 & 39.3 & 6.0 & 143 & 5.6 \\
\hline 30 & 36.8 & 11.5 & 261 & 10.3 \\
\hline 40 & 31.8 & 22.3 & 462 & 18.3 \\
\hline 50 & 21.1 & 45.6 & 793 & 31.3 \\
\hline 55 & 10.5 & 68.7 & 1030 & 40.7 \\
\hline
\end{tabular}

If additionally a flux of nitrogen is used to cool compressors at the air separation unit and to increase its temperature, then its capacity to absorb moisture significantly increases. After heating up a flux of nitrogen up to $55{ }^{\circ} \mathrm{C}$, the moisture of lignite in the analysed case is reduced to about $10 \%$ and this is the minimal value for which it is possible to dry coal at a standard drying unit (station), since the remaining water is molecularly bonded [8]. In this case, the calorific value of lignite increases by almost $70 \%$ and thus reduces the consumption of coal by about $40 \%$. In case of the heat block with its electrical power at $100 \mathrm{MW}$, an amount of used coal is reduced by about 1000 t/day.

\subsection{Accumulation of energy in liquefied nitrogen}

If the gases separated from air are used in a short distance from ASU, they are usually delivered in gaseous form. In cryogenic installations the gases leaving the rectification column are warmed up in recuperative heat exchangers thus precooling the feed air and limiting the energy required for air separation. If the separated gases are removed from the ASU in liquid form, the energy consumption increases by $3-4$ times, up to $600-800 \mathrm{kWh} / \mathrm{t}$ $\mathrm{O}_{2}$. This surplus energy can be later partly recovered. It is hence possible to treat liquid oxygen and liquid nitrogen as energy accumulators, what may be important in case of variable demand for electrical energy resulting, e.g., from over-scaled installation of renewable energy sources like wind mills and 
photovoltaic panels. The efficiency of liquid gas based energy accumulator depends on the technology of the gas regasification.

One of the technologies for the liquid nitrogen (LIN) regasification with energy recovery is its pressurization in liquid form, warm up using environment as a heat source in a high pressure heat exchanger, and turbine expansion. The expansion can be in single or multistage system. The process is schematically depicted in Fig. 3 for single, two- and three-stage serial system.
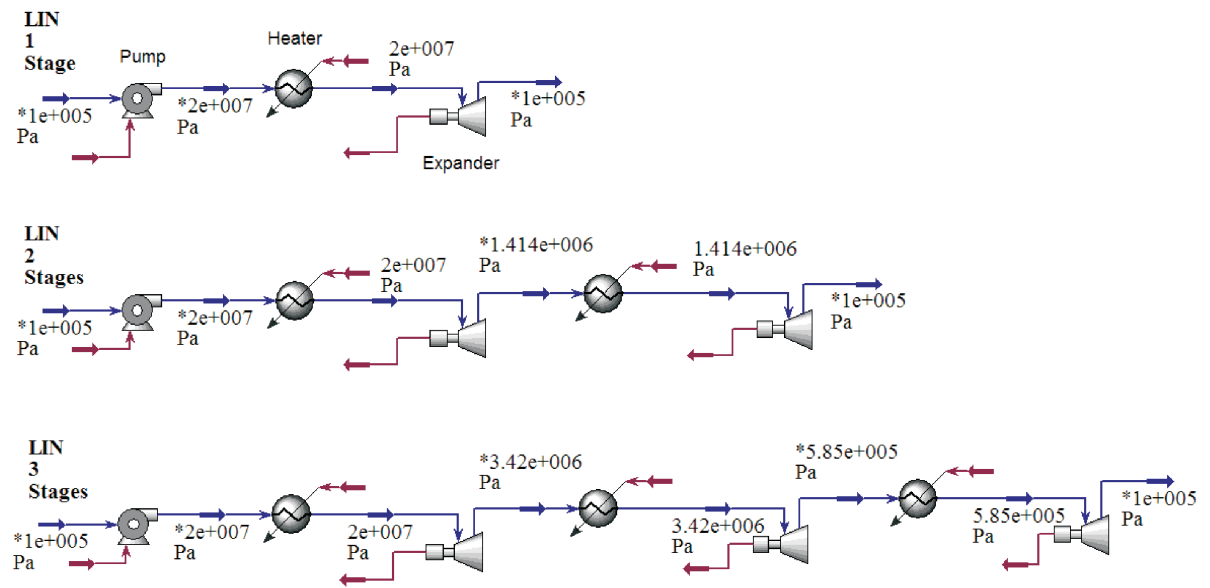

Figure 3: The idea of pressurized regasification of liquid nitrogen in single, two- and three-stage serial system.

Due to the fact that the liquid compression is much less energy demanding then the compression of the gas, the energy of expansion exceeds significantly the energy of compression - compare Fig. 4. It is seen that the maximum of net power for a single expansion is achieved when the nitrogen is pressurized to $6-7 \mathrm{MPa}$. The effect of energy recovery can be augmented by the use of multistage expanders with intermittent warm up of the gas see Fig. 5. Using the concept depicted in Fig. 3, it is possible to recover as much as $85 \%$ of liquid nitrogen physical exergy, about $35 \%$ as mechanical work and $50 \%$ as cooling power [9].

\section{Conclusions}

Potential implementation of oxygen combustion in thermal power plants would create a demand of oxygen exceeding the present Polish production 


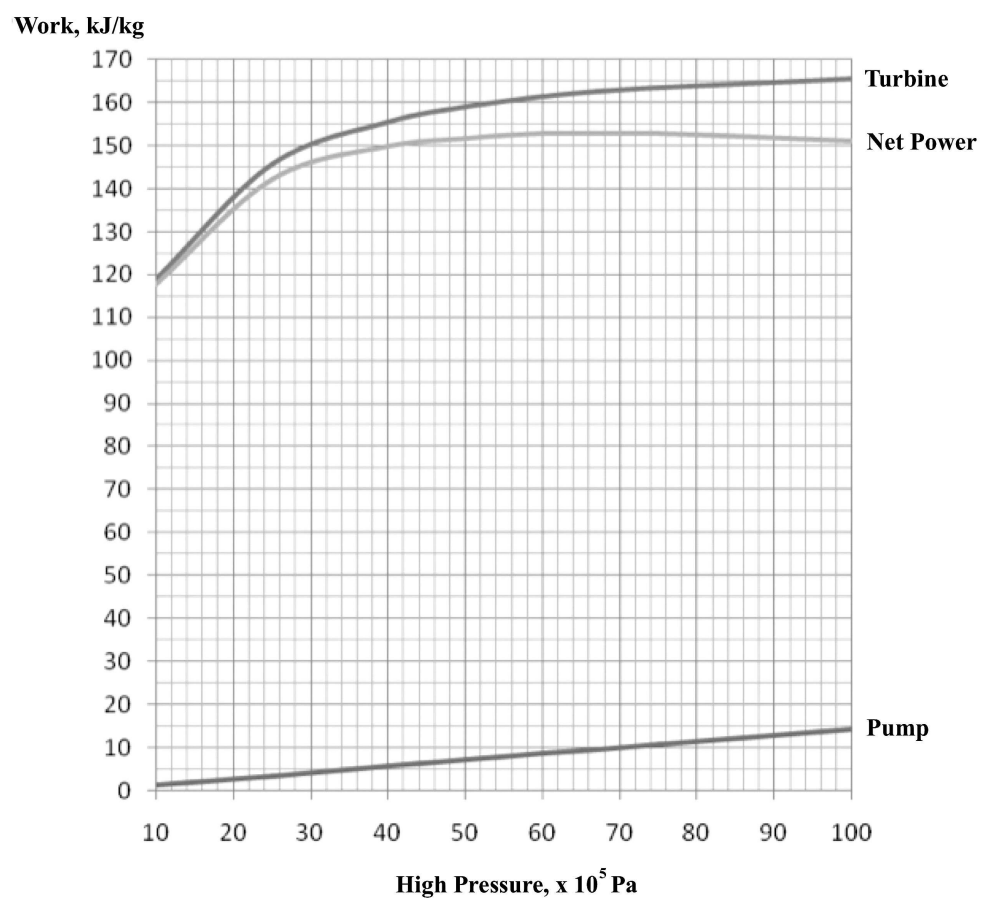

Figure 4: The possibility of mechanical energy recovery in pressurized regasification process (single stage), pump - energy used for the liquid nitrogen pressurization, turbine - energy recovered during warm gas expansion.

of this gas by two orders of magnitude. The required quantities can be achieved in cryogenic air separation plants characterized be relatively low energy consumption, but still exceeding thermodynamic minimum by three to four times and causing thermal power plant efficiency drop by at least $7 \%$. This can be partly compensated by utilization of the air separation by-products namely gaseous and liquid nitrogen. Gaseous nitrogen can be used for lignite drying, especially after its warm up with heat recovered from the air compressors. Liquid nitrogen can be used as energy accumulator allowing recovery up to $85 \%$ of physical exergy of cryogen.

Acknowledgements This work has been supported by the National Centre for Research and Development, as Strategic Project PS/E/2/66420/10 Advanced Technologies for Energy Generation: Oxy-combustion technology for $P C$ and $F B C$ boilers with CO2 capture and statutory funds from Ministry for Science and Higher Education (S-10057/I-2201). 


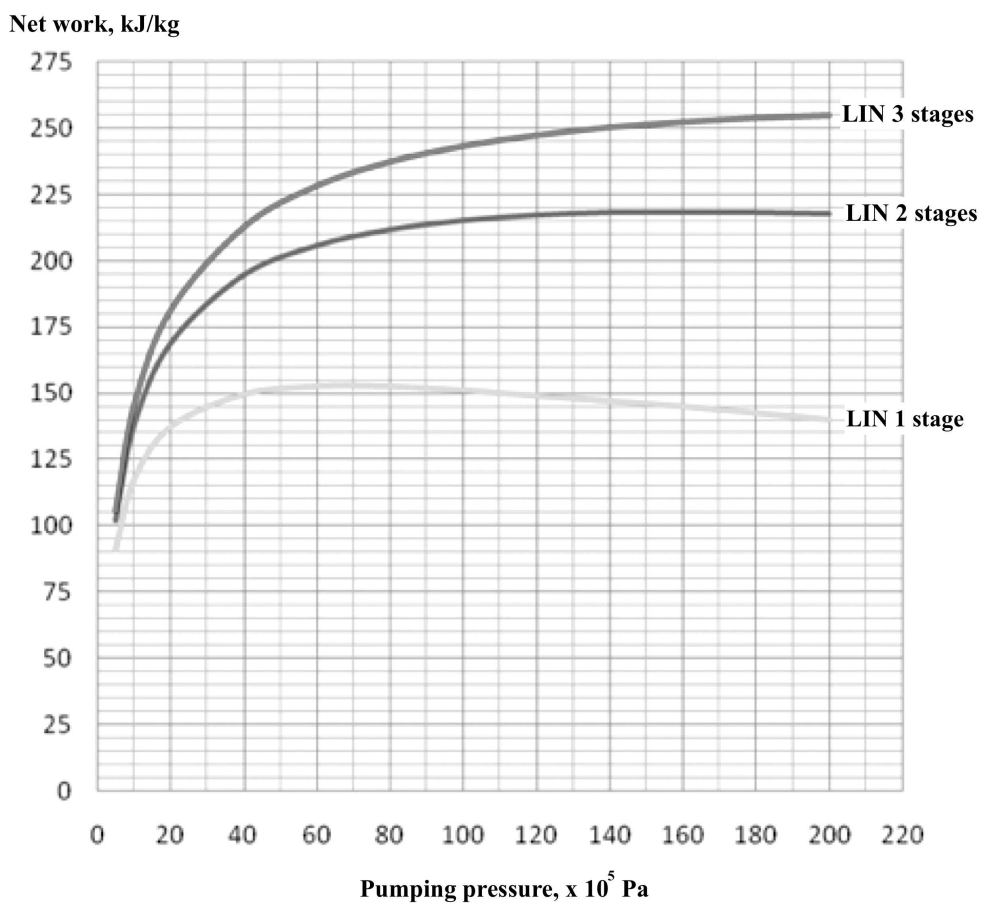

Figure 5: Mechanical energy recovery in multistage expansion of liquid nitrogen.

Received 10 December 2014

\section{References}

[1] Chorowski M.: Cryogenics - basics and applications. IPPU MASTA, Gdańsk 2007 (in Polish).

[2] Chorowski M., Gizicki W.: Oxygen production for oxy-combustion applications. In: Proc. of ICEC 24-ICMC 2012, May 14-18, 2012, Fukuoka, Japan, Cryogenics and Superconductivity Society of Japan, 2013.

[3] Wilkinson M.B., Boden J.C., Panesar R.S., Babcock M., Allam R.J.: $\mathrm{CO}_{2}$ capture via oxyfuel firing: Optimisation of a retrofit design concept for a refinery power station boiler. 1st Nat. Conf. on Carbon Sequestration. Washington DC, USA, May 15-17, 2001.

[4] Fu C., Gundersen T.: Optimized air separation units for oxy-combustion processes. In: Proc. of the 23rd IIR Int. Congress of Refrigeration, Prague, Aug. 21-26, 2011.

[5] Li H., Hu Y., Ditaranto M., Willson D., Yan J.: Optimization of cryogenic $\mathrm{CO}_{2}$ purification for oxy-coal combustion. Energy Procedia 37(2013), 1341-1347. 
[6] Prosser N., Shah M.: Air separation for oxy-coal power plants. In: Proc. of the 2nd Oxyfuel Combustion Conference, Queensland, Australia, Sept. 12-16, 2011.

[7] Belaissaoui B., Le Moullec Y., Hagi H., Favre E.: Energy efficiency of oxygen enriched air production technologies: Cryogeny vs membranes. Sep. Purif. Technol. 125(2014), 142-150.

[8] Lichota J., Plutecki Z., Pawlak-Kruczek H., Anweiler S., Nowosielski G.: Mathematical modeling of fluidized bed lignite dryers. In: Proc. of the 38th Int. Tech. Conf. on Clean Coal and Fuel Systems, June 2-6, 2013, Clearwater, Florida, Coal Technologies Associates, 2013.

[9] Wróblewski M.: Cryogenic installations coupled with energy recovery systems. MSc thesis, Wroclaw University of Technology, Wroclaw 2014 (in Polish). 